\title{
Complex Adaptive Systems Modeling: A multidisciplinary Roadmap
}

Muaz A Niazi

\section{Correspondence:}

muaz.niazi@gmail.com Present address: Bahria University, Shangrila Road, E-8, Islamabad, Pakistan

\section{Springer}

Keywords: Complex networks, Agent-based modeling, Complex adaptive systems, Complex adaptive systems modeling, Social network analysis, Biological networks, Ecological networks, Citation networks, Individual-based modeling

PAC Codes: $07.05 . T p, 89.75 .-k$, 89.75.Fb

Mathematics Subject Classification (2010): 05C82, 68T42, 00A72, $92 \mathrm{C} 42$

\section{Complex AdaptiveSystems Modeling}

I would like to start by extending a very warm welcome from the editorial board of Complex Adaptive Systems Modeling (CASM) journal, a new and exciting SpringerOpen/BioMed Central project. This article is the opening editorial and a call for papers for CASM. It also provides a gentle introduction to CASM as well as serves as a concise multidisciplinary roadmap and survey for CASM readership. The primary goal is to assist multidisciplinary researchers with an interest in modeling complex systems in finding more about relevant helpful resources and the numerous exciting ways in which other colleague researchers use modeling approaches in their respective disciplines. Finally I also provide advice for prospective authors regarding the preparation of manuscripts in a style appropriate to the highly multidisciplinary CASM readership. It is hoped that this will help seed fruitful cross-fertilization of ideas transgressing disciplinary boundaries.

Briefly, as a journal, CASM has several unique features :

1. A shorter peer-review time.

2. Open access publication with global visibility.

3. Online only journal with rapid publication.

4. A focus on well-written articles readable by multidisciplinary researchers.

5. Publication scope encompassing two key paradigms for modeling Complex Adaptive Systems: Agent-based Modeling and Complex Networks.

6. Highly multidisciplinary editorial board with researchers ranging from ecology to biology and from the social sciences to computer sciences.

As such, while there are several other complexity-related journals, CASM is unique in several ways; firstly, because CASM is primarily concerned with articles in two key modeling and simulation paradigms for Complex Adaptive Systems (CAS); systems

(c) 2013 Niazi; licensee Springer. This is an Open Access article distributed under the terms of the Creative Commons Attribution License (http://creativecommons.org/licenses/by/2.0), which permits unrestricted use, distribution, and reproduction in any medium, provided the original work is properly cited. 
which can be better understood as a notion rather than a strict definition (more on this later). Secondly, CASM is open access; open access implies visibility to a global audience allowing readers to freely access all articles without paying any article or subscription fees. In addition, CASM is an initiative under SpringerOpen/BioMed Central, a well-established open access platform publishing several high quality and impact factor journals such as BMC Bioinformatics (impact factor: 2.75) and BMC Biology (impact factor: 5.75).

Another unique feature of CASM is our goal to minimize review times as much as practically possible. We hope to achieve this by having a stricter scope and stringent cover letter requirements. CASM aims to serve as a high quality publication venue for a multidisciplinary readership of researchers interested in these two modeling and simulation paradigms for CAS; Agent-Based Modeling (ABM) (Holland 2006) and Complex Networks (CN) (Mitchell 2006). CASM is therefore open to papers from these two distinct communities of multidisciplinary researchers with an underlying common interest in modeling the same type of systems i.e. CAS. Thus, quite simply, any paper would be in the scope of CASM as long as it has been written with a clear focus on CAS using at least any one of these two modeling paradigms of interest. A discussion of the widespread nature and multidisciplinary interest in these paradigms will be provided in later sections of this article.

\section{Outline}

The article first outlines general guidelines for submissions to CASM in the section "Guidelines for submissions". This is followed by an overview of the two paradigms of interest and a multidisciplinary survey of literature. Finally, the paper is concluded.

\section{Guidelines for submissions}

Aims \& scope

CASM is a highly multidisciplinary modeling and simulation journal that serves as a unique forum for original, high-quality peer-reviewed papers with a specific interest and scope limited to agent-based and complex network-based modeling paradigms for CAS. The scope of CASM essentially spans any and all domains of CAS. Possible areas of interest include the Life Sciences (E.g. Biological Networks and agent-based models), Ecology (E.g. Agent-based/Individual-based models), Social Sciences (Agent-based simulation, Social Network Analysis), Scientometrics (E.g. Citation Networks) to large-scale Complex Adaptive COmmunicatiOn Networks and environmentS (CACOONS) such as Wireless Sensor Networks (WSN), Body Sensor Networks, Peer-to-Peer (P2P) networks, pervasive mobile networks, service oriented architecture, smart grid and the Internet of Things. A paper in these areas is welcome as long as it uses either an agent-based (simulation) and/or complex-network based modeling approach.

\section{Keywords}

For reference, here I would like to give a sampling of alphabetically arranged keywords which may be of interest to CASM readership:

agent-based models, agent-based simulation, artificial life, biological networks, Boolean networks, citation networks, complex adaptive systems, complex network analysis, 
complex networks, computer networks, emergence, epidemiological networks, gene expression networks, gene regulatory networks, individual-based modeling, metabolic networks, (agent-based modeling of) multiagent systems, network modeling, nucleic acid networks, protein interaction networks, self-adaptation, self-assembly, self-healing, selforganization, signaling pathway networks, social network analysis, social networks, social simulation, systems biology.

\section{General guidelines for article submissions}

Any paper submitted to CASM should have the following elements:

1. A strict adherence to the aims and scope of CASM.

2. A solution to an interesting problem or a review of recent literature.

3. A comparison of results with existing work from the state-of-the-art.

4. Enough details for the readers to be able to replicate the results.

5. A well-written and thoroughly edited/proof-read coherent piece of writing.

6. Adherence to general ethical guidelines both in terms of data as well as in terms of authorship.

7. A clear focus on the following two key elements:

(a) At least one specific area of CAS (E.g. ecology, social sciences, large scale communication networks, biological sciences etc.)

(b) At least one of the two paradigms of interest:

i. Agent-based Modeling

ii. Complex Network modeling.

8. CASM has a strongly multidisciplinary editorial board and readership. Therefore authors need to ensure that their articles have been written in a style that is comprehensible by a broad and multidisciplinary audience. Authors are advised to avoid excessive usage of domain-specific jargon/terminologies unless all such terms have been formally introduced at the start of the article. In addition, any domain-specific concepts must be explained in the article and the authors should not assume any advanced knowledge on the part of the readers. Thus, as an example, an article on Gene Regulatory Networks should be written in a style accessible to a number of social science researchers using Social Network Analysis and vice versa. Likewise an article written by Computer Scientists for Wireless sensor networks must also take into consideration CASM readership of researchers from Social and Biological Sciences and so on. Interested readers are advised to consult an excellent article on this topic by Hoffman (Hoffman 2006).

\section{Example topics in complex networks}

- All types of complex networks such as biological, social, citation, ecological networks etc.

- Agent-based modeling using an ABM tool (such as NetLogo, RepastS etc.) of CACOONS such as modeling concepts related to the internet, intranet, P2P, ad-hoc and Wireless Sensor Networks as networks/graphs.

- Network generation, visualization, modeling and simulation. 


\section{Example topics in agent-based models}

- Agent-based Modeling case studies in ecology, business, biology, social sciences, operations research, economics, computer sciences, communication networks, artificial intelligence, robotics etc.

- Software engineering of agent-based and complex network models.

- Verification and validation of agent-based and complex network models.

- Exploratory agent-based models for conducting feasibility and proof-of-concept studies.

- Agent-based models and their respective DescRiptivE Agent-based Models (DREAM) (Niazi 2011) a or text based descriptions of models (E.g. the ODD protocol (Grimm et al. 2006)) for inter-disciplinary model comparisons.

- Validated agent-based models for verified and validated models such as using empirical validation approaches or VOMAS (Niazi et al. 2009) or any other methodology.

\section{Papers which may be rejected without formal review}

Submissions which are not in line with the above criteria or those which are of a purely or largely theoretical/formal/mathematical nature or have been written in a very domainspecific style may be considered as out of scope of CASM and rejected without review. Here are some obvious examples of manuscripts which may be rejected without review:

1. Manuscripts which are not written in a style suitable for a multidisciplinary audience.

2. Papers with a focus on software multiagent systems without any relation to agent-based modeling from the CAS perspective. These would perhaps be out of scope for CASM and perhaps more suited to the scope of Springer's "Autonomous agents and multiagent systems" journal.

3. Communication network papers which use simulators (such as OPNET, OMNET ++, Matlab, custom simulators in programming languages etc.) with little or no relation with agent-based modeling would perhaps be more suitable for communication networks journals such as the Springer "Peer-to-Peer Networking and Applications", Springer "Wireless Networks" or "EURASIP Journal on Wireless Communications and Networking" amongst others.

4. Papers written with only a formal/mathematical perspective without any focus on an $\mathrm{ABM}$ or a $\mathrm{CN}$ model.

5. Papers which are poorly organized or written.

6. Papers which include plagiarized material.

\section{Editorial process}

Having a highly multidisciplinary following and a clear focus on the two modeling techniques for CAS requires adherence to a somewhat stringent editorial policy. These include cover letter requirements as well as a clear adherence to the aims and scope. In addition, only such submitted papers will be reviewed which have a clear focus on modeling CAS and have been written with a writing style understandable by a broad audience. Each paper is handled according to an editorial flow which may be roughly depicted in Figure 1. It may also be noted that papers submitted to CASM may be checked using CrossRef/iThenticate for possible plagiarism before a formal review. 


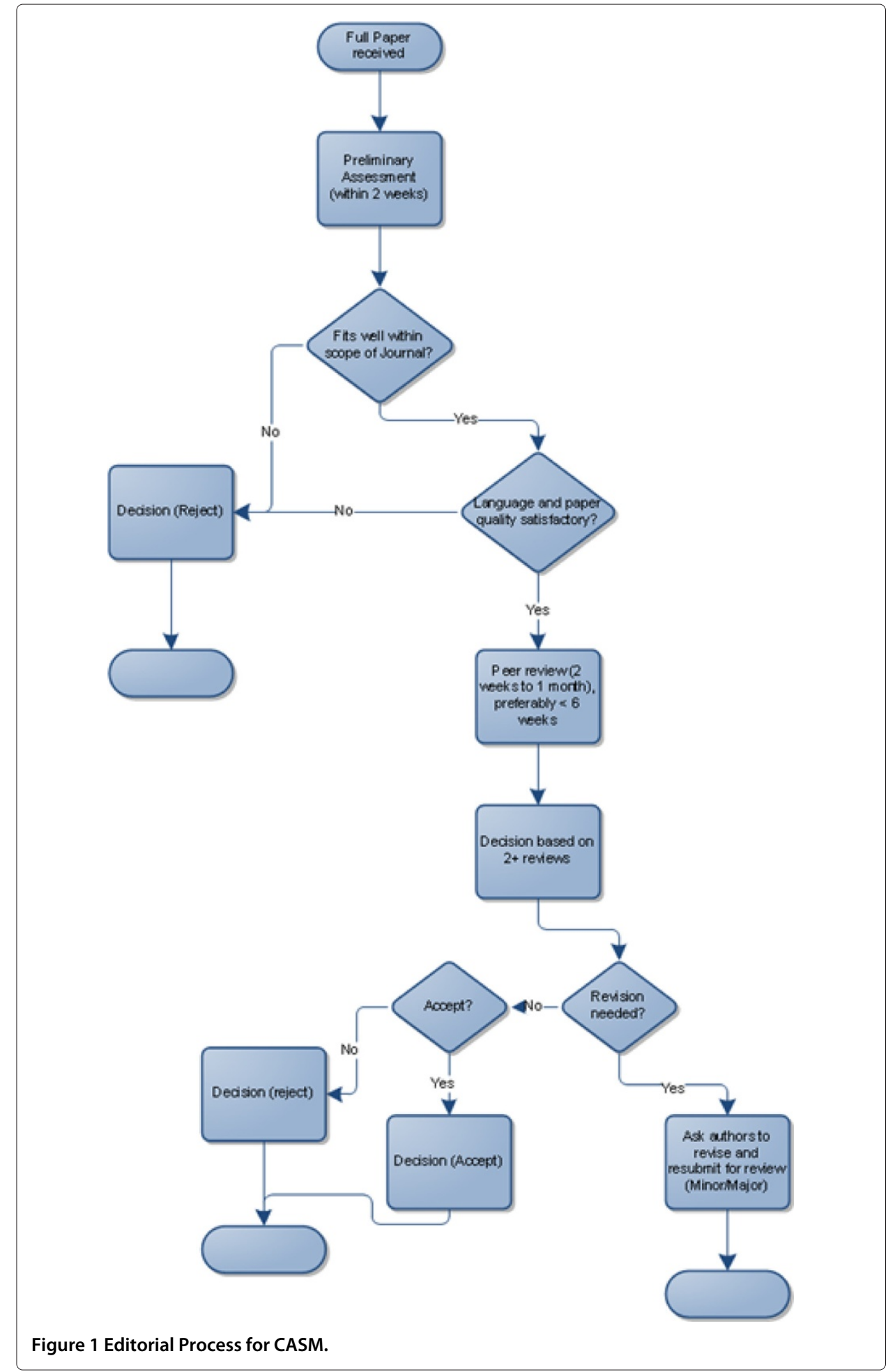

\section{Cover letter requirements}

In some journals, cover letters are considered a formality however, a well-written cover letter is one of the essential requirements for any submission to CASM. The cover letter may also help the editors in ensuring an adherence of the paper with publication ethics guidelines outlined by $\mathrm{COPE}^{\mathrm{b}}$ : 
1. Names and contact details of all authors.

2. A single sentence summarizing the research contribution and significance of the paper in comparison with previous work (With 2-3 related references).

3. CASM strongly discourages redundant submissions. If there is any other related paper (by one of the authors) either currently under review in another venue (conference, workshop or journal etc.) or else has already been published/in press, then the cover letter must include a statement of changes which make the submitted paper different from that paper. The authors may briefly summarize how the submitted paper differs from the other paper(s). In addition, since the reviewers may not have access to the full text of the other paper(s), it is important to attach a soft copy of the paper during the manuscript submission process allowing the referees to evaluate the significance of the changes.

4. A brief list of individual contribution details of each author; essentially each author must have contributed significantly to the paper and all people who have contributed significantly must be listed as authors. Ghost, Gift, and other forms of unethical practices are strongly discouraged ${ }^{c}$.

5. The cover letter may also note the corresponding author's justification of the particular order of authors. If the editorial office is not satisfied with this order, the authors may be asked to change the author order before or at any time during the formal manuscript handling process.

6. To ensure that the paper is not rejected as being out-of-scope, it is important to also briefly answer the following questions in the cover letter:

(a) Which particular discipline (related to CAS) is being explored in the manuscript? (E.g. social sciences, economics, ecology, biology, CACOONS etc.)?

(b) Which particular modeling technique is being used in the paper? (E.g. To be within scope, the paper must have either or both of Agent-based Simulation Model or Complex Networks).

(c) Which particular modeling tool was used in the study? NetLogo (Wilensky 1999), Repast (North et al. 2007), Swarm (Minar et al. 1996), Network Workbench (Team 2006), Pajek (Batagelj and Mrvar 1998), Cytoscape (Shannon et al. 2003), Gephi (Bastian et al. 2009), Visone (Baur et al. 2002) or CiteSpace (Chen 2006) etc.

(d) If the area of the paper is agent-based modeling then give details of how the verification and validation were conducted. This could include techniques such as empirical validation (Windrum et al. 2007) or validated agent-based modeling using a VOMAS (Niazi 2011) or any other technique suitable for ABM.

\section{Modeling CAS}

In this section, we briefly examine concepts related to CAS and the two modeling and simulation paradigms forming the scope of CASM.

CAS

The CAS concept is married to the interaction of a set of perhaps simple but numerous entities, components or agents which interact and adapt on the basis of non-linear 
interactions (Miller and Page 2007). This interaction is known to give rise to interesting and emergent phenomena. While it is rather difficult to contain all aspects of CAS in a single definition, our current understanding is that CAS are often found in nature and in nature-inspired artificial systems in close relation with or inspired by life in some way, a notion exemplified in one of the earliest definitions of CAS by Cowan and Feldman (1986):

"Systems comprising large numbers of coupled elements the properties of which are modifiable as a result of environmental interactions"

CAS concepts are tied to an abstract concept of a society. As such, it can be noted that typical research articles with a focus in modeling CAS are ornate with the following concepts:

1. A large number of agents (E.g. Genes, societies, humans, animals, insects, software agents, data packets etc.).

2. Focus on somewhat simpler individual agents.

3. Focus on the nonlinear interaction between agents and global phenomena resulting from these interactions.

\section{Agent-based modeling}

In $A B M$, the basic idea is to develop a simulation model at some level of abstraction using concepts which represent interacting entities in the system to be modeled. ABM can range from Cellular Automata (CA) such as shown in Figure 2a to models with mobility such as shown in Figure 2b. Other examples include networked agents such as can be seen in Figure 2c.

Different activities which are associated with developing an ABM are similar to those required in a regular simulation model. However, there are some additional concepts required for modeling and simulation of CAS (Niazi and Hussain 2012). Banks and Chwif give general warnings about using simulation for manufacturing and some other areas in (Banks and Chwif 2010). Macal and North present successful approaches for teaching agent-based simulation in (Macal and North 2012). A tutorial on ABM has been presented in (Macal and North 2010). Railsback et al. gives an overview of Agent-based modeling platforms in (Railsback et al. 2006).

\section{Complex networks}

In terms of complex networks, the focus of studies is typically on data retrieved from the interactions of various CAS agents/components. So, while agent-based models are dynamic models, complex networks are typically developed from a large amount of data. The actual data sources can be as diverse as bio-chemical reactions, gene expressions, social networks, human cell phone mobility or even citation data etc. Activities in complex networks range from modeling, simulation, analysis and visualization of networks. Three different examples of using complex networks are given in Figure 3. Figure 3a shows the use of citation networks to analyze research areas using agent-based modeling. Figure $3 \mathrm{~b}$ shows the structure of a retroviral RNA modeled as a complex network. Likewise, Figure 3c show the social network of top-cited authors in the consumer electronics domain. 


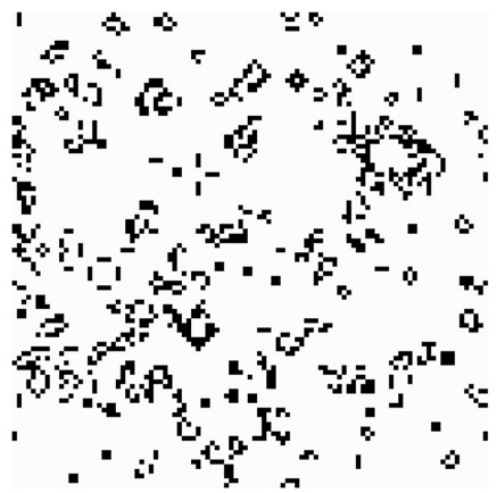

(a)

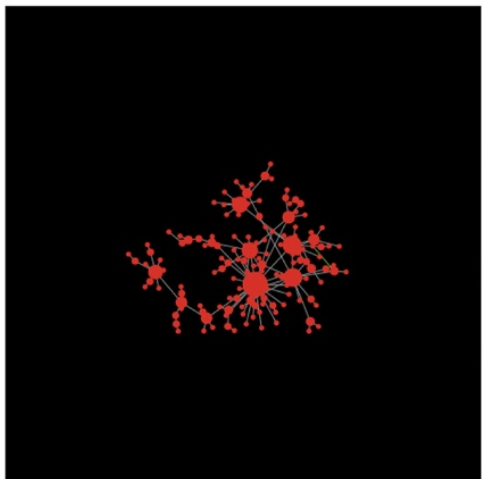

(c)

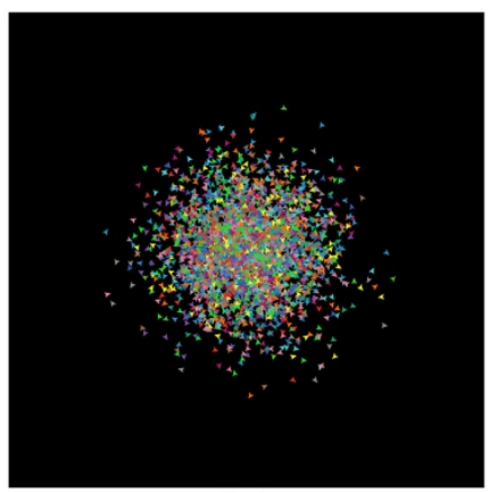

(b)

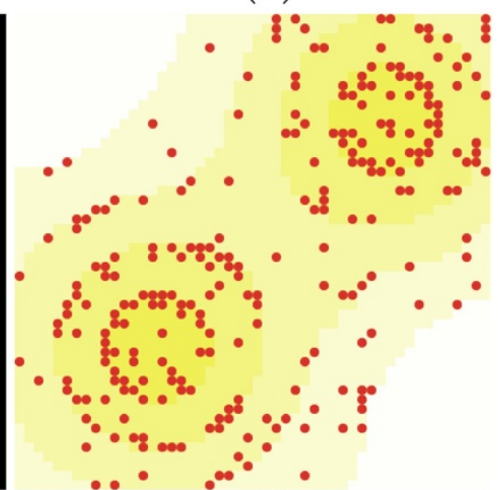

(d)

Figure 2 A sampling of different types of ABM using NetLogo. (a) Cellular Automata Model, (b) Mobile agents in an ABM, (c) Networked agents and (d) Sugarscape model in NetLogo.

\section{A multidisciplinary road map}

In this section, I shall give an overview of literature spread across various disciplines but having a focus on either Agent-based Modeling or Complex Network-based methods.

\section{Social sciences}

\section{$A B M$}

Agent-based modeling has found extensive usage in social sciences. Epstein and Axtell present a social sciences model for a society called Sugarscape (Epstein and Axtell 1996) as can be seen in Figure 2d. Bonabeau has noted ABM as an effective set of methods and techniques for simulating human systems (Bonabeau 2002). Kohler notes a clear focus on ABM in anthropology and sociology but does not note its significance in comparison with differential equation models (Kohler 2000). This work also notes skepticism towards simulation in general and ABM in particular. However, we may note that recent advances in validation and verification of models (Niazi et al. 2009) are focused on alleviating these problems such as discussed in (Miller and Page 2007).

Likewise Macy and Willer (Macy and Willer 2002) note that while sociologists often model processes in social sciences as interactions of mathematical variables, they have discovered $\mathrm{ABM}$ to be an alternate approach to modeling social life as interactions among influential and responsive agents. Gimblett demonstrates the integration of ABM with Geographical Information Systems (GIS) and its application on social and ecological data 


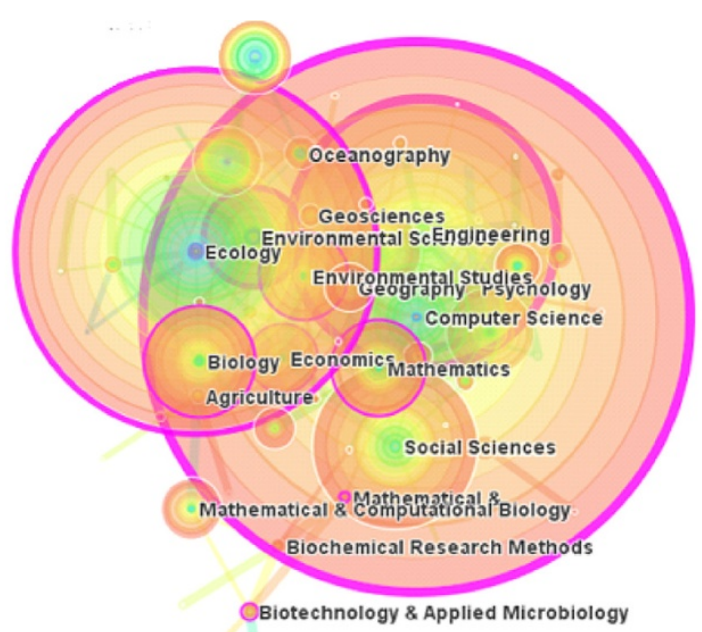

(a)

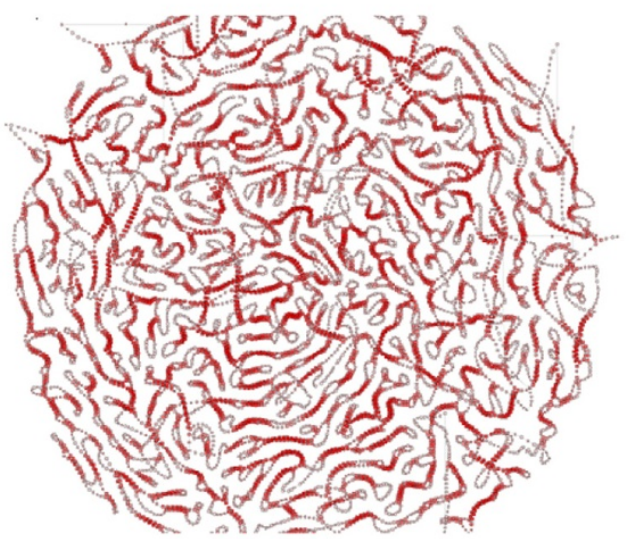

(b)

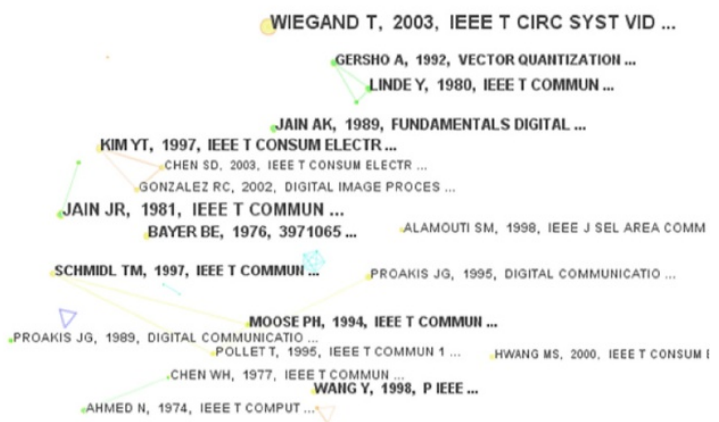

(c)

Figure 3 Example Complex Networks created using different tools from multidisciplinary data. (a) Complex network showing the prevalence of agent-based modeling in using scientometric data from ISI web of knowledge (Niazi and Hussain 2011 b), (b) Complex Network of the entire genome of the RNA-based Feline Immunodeficiency Virus folded using RNAStructure and then plotted using NWB (Reuter and Mathews 2010) and (c) Social Network of the authors of top cited papers in the Consumer Electronics Domain (Niazi and Hussain 2011d). 
(Gimblett 2002). Axelrod gives an overview of simulation in the social sciences (Axelrod and Tesfatsion 2006). More recent work includes (Gilbert and Troitzsch 2005). Davidson gives a Computer Sciences perspective to ABM (Davidsson 2002). Other recent work includes ABM for human socio-cultural behavior by Jiang et al. in (Jiang et al. 2012). A recent special issue on complex social systems was edited by Lopez et al. (López-Paredes et al. 2012). Another source of valuable information in the application of ABM is the journal JASSS. Tesfatsion has given an overview of developing agent-based models of computational economics in (Tesfatsion 2002,2003; Tesfatsion and Judd 2006). Whereas Luna and Stefansson give an overview of using Swarm as platform for economic simulations in (Luna and Stefansson 2000). Modeling of driver route behavior in transportation research is given by Dia in (Dia 2002). A tutorial on using ABM in social sciences has been presented by North and Macal in (North and Macal 2007).

CN

Publications with a focus on social networks are present in high-ranking journals such as the Proceedings of the National Academy of Sciences (Lewis et al. 2012). Earlier articles include one by Scott (1988) which argues the importance of the social network model. A relevant special issue in the 90's gave directions to the field in political sociology, interorganizational relations, social support, social influence, and epidemiology (Galaskiewicz and Wasserman 1993). A book and reference on the topic is by Yang and Knoke (2008). Another recent book on the topic is (De Nooy et al. 2011). There are other recent reviews such as the one by McGloin and Kirk in (McGloin and Kirk 2010). Gardy et al. use social network analysis in a tuberculosis network (Gardy et al. 2011). In case of supply chain networks, network analysis has been used by Kim et al. in (Kim et al. 2011). Suer et al. demonstrate how the use of networks can improve studies of primate behavior (Sueur et al. 2011).

\section{Computer sciences}

$A B M$

Agents have always been considered an integral part of artificial intelligence as exemplified by the classic artificial intelligence text by Russell and Norvig, often labelled as the "Agent book" (Russell and Norvig 2010). However, the exact notion of agency is often quite different in CAS as compared to multiagent systems (which are traditionally software agents) as compared with agents in an agent-based model which represent entities from the real world (Niazi and Hussain 2011b).

The particular sub-section of multiagent systems which has an overlap with agent-based modeling is the development of simulation models of multiagent systems using agentbased modeling tools such as NetLogo, RepastS, Swarm and Mason amongst others. In addition, agent-based models may be developed for other artificial CAS such as Wireless Sensor Networks, Swarm Robotic Networks, Self-assembling robots, Peer-to-peer networks and others. Due to a lack of any other term to classify these networks, we classify this set of communication networks as Complex Adaptive COmmunication Networks and environment $S$ (CACOONS). Examples include work by Vidal (2006). Agent-based tools have also been identified as effective in teaching multiagent concepts (Vidal et al. 2004) as well as developing experimental simulations of multiagent systems (Sklar 2007). Agent-based models have also been developed for wireless sensor networks (Niazi and 
Hussain 2011a, 2011c) as well as for modeling self-organizing and large-scale communication networks (Niazi et al. 2009). A methodology for using simulation as a means of developing distributed agent systems has been present by Fortino and Russo in (Fortino and Russo 2012).

CN

Communication networks have a long history of being represented as graphs. Graphs are a precursor of complex networks since networks are essentially graphs "loaded" with additional information. Earlier work such as the famous algorithm by Dijkstra has also used graphs/networks (Dijkstra 1959). Use of social network analysis in sensors has been shown in (Tsugawa et al. 2012). Other examples include graph-based models for mobility by Tian et al. in (Tian et al. 2002) and models of internet topology by Calvert et al. in (Calvert et al. 1997). Another interesting aspect of using agents is as a means of programming Wireless Sensor Networks presented by Aiello et al. in (Aiello et al. 2011).

\section{Life sciences and ecology}

$A B M$

Grimm et al. present (Holcombe et al. 2012) pattern-oriented modeling by giving a unifying framework for deciphering the internal details of agent-based models of CAS (Grimm et al. 2005). Mansury et al. (2002) develop an ABM of "spatio-temporal search and agglomeration" to investigate "cell motility" dynamics as well as "aggregation" with the expectation of a CAS nature of tumors. Recently ABM has been explored in synthetic biology by Krishnamurty in (Krishnamurthy ). Holcombe et al. note the strength of using ABM to model complex biological systems. Read et al. present an approach to calibration of an agent-based model of EAE, "a mouse proxy for multiple sclerosis" (Read et al. 2012). Qu et al. present a digital orange tree simulation using an ABM ( $Q u$ et al. 2012). Another work by Høye et al. demonstrates systematic modification of the digital version of a real landscape to produce artificial landscapes (Høye et al. 2012). Iantovics presents a large-scale hybrid medical diagnosis system (Iantovics 2012). An introduction to ABM in the domain of life sciences and ecology is by Railsback and Grimm in (Railsback and Grimm 2011).

CN

Biological networks are often studied in terms of their community structure similar to social networks (Girvan and Newman 2002). Efficient algorithms for identifying Boolean networks and related biological networks from DNA micro-array data have been proposed by Akutsu et al. in (Akutsu et al. 2000). Complex network tools such as Cytoscape enable conversion of biological data to complex networks (Cline et al. 2007). Cytoscape has a number of plug-ins allowing data retrieval from different databases as well as for performing other tasks (Maere et al. 2005). Among other methods, process diagrams have also been used to represent biological networks (Kitano et al. 2005). Different techniques have also been developed to co-cluster biological networks with gene expression data such as in (Hanisch et al. 2002).

VANTED is a tool for the visualization as well as structural analysis of biological networks usable for correlating with experimental data from biochemical experiments (Junker et al. 2006). Another option for the discovery of useful scientific information in 
biological networks is the utilization of topological motif structure discovery (Shen-Orr et al. 2002; Milo et al. 2002) in gene regulatory networks or protein interaction maps (Berg and Lassig 2004).

\section{Conclusions}

In this article, I have presented a multidisciplinary road map as well as an overview of Agent-based Modeling and Complex Networks for the modeling and simulation of Complex Adaptive Systems. I have also introduced CASM, a new multidisciplinary SpringerOpen/BioMed Central journal with aims and scope in these two areas. CASM reflects a high quality peer-reviewed venue for multidisciplinary researchers interested in ABM and CN. CASM also offers a faster publication time as well as a broad scope and an open access publication model. As such, quite simply, any submitted paper will be in the scope of CASM as long as it has a focus on the modeling and simulation of a CAS using either or both of $\mathrm{ABM}$ and $\mathrm{CN}$ methods.

\section{Endnotes}

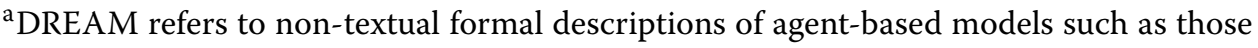
obtained by converting agent-based models to complex networks and subsequently applying quantitative centrality measures.

bhttp://publicationethics.org/resources/guidelines

${ }^{\mathrm{c} F o r}$ reference, kindly review http://publicationethics.org/files/u2/2003pdf12.pdf

Competing interests

The authors declare that they have no competing interests.

\section{Acknowledgements}

I would like to thank the SpringerOpen/BioMed Central team in general and our Springer editor Matthew Amboy, in particular for their untiring efforts in helping develop CASM from an idea to a reality. I would also like to specifically thank (listed alphabetically) Prof. Lubomir Chitkusev, Dr. Carlos Gershenson, Prof. Michael Huhns, Prof. Amir Hussain, Prof. Tuncer Ören, Prof. José M. Vidal, Prof. Anatoly Temkin and Prof. Tanya Zlateva for their continual advice, critique and support.

Received: 5 August 2012 Accepted: 6 August 2012 Published: 13 March 2013

References

Aiello, F, Fortino G, Gravina R, Guerrieri A: A Java-based Agent Platform for Programming Wireless Sensor Networks. Comput J 2011, 54(3):439-454 doi:10.1093/comjnl/bxq019.

Akutsu, T, Miyano S, Kuhara S: Algorithms for identifying Boolean networks and related biological networks based on matrix multiplication and fingerprint function. J Comput Biol 2000, 7(3-4):331-343.

Axelrod, R, Tesfatsion L: Guide for Newcomers to Agent-Based Modeling in the Social Sciences. In Handbook of Computational Economics, Vol. 2: Agent-Based Computational Economics. Edited by Tesfatsion, L, Judd K. New York: North-Holland; 2006:1647-1659.

Banks, J, Chwif L: Warnings about simulation. J Simulation 2010, 5(4):279-291.

Bastian, M, Heymann S, Jacomy M: Gephi: An Open Source Software for Explor- ing and Manipulating Networks. In Proceedings of the Third International ICWSM Conference (2009); 2009.

Batagelj, V, Mrvar A: Pajek-program for large network analysis. Connections 1998, 21(2):47-57.

Baur, M, Benkert M, Brandes U, Cornelsen S, Gaertler M, Köpf B, Lerner J, Wagner D: Visone Software for visual social network analysis. In Graph Drawing. Vienna, Austria: Springer; 2002:554-557.

Berg, J, Lässig M: Local graph alignment and motif search in biological networks. Proc Nat Acad Sci USA 2004, 101(41):14689.

Bonabeau, E: Agent-based modeling: Methods and techniques for simulating human systems. Proc Nat Acad Sci USA 2002, 99(Suppl 3):7280.

Calvert, K, Doar M, Zegura E: Modeling internet topology. Commun Mag, IEEE 1997, 35(6):160-163.

Chen, C: CiteSpace II: Detecting and visualizing emerging trends and tran- sient patterns in scientific literature. J Am Soc for Inf Sci Technol 2006, 57(3):359-377.

Cline, M, Smoot M, Cerami E, Kuchinsky A, Landys N, Workman C, Christmas R, Avila-Campilo I, Creech M, Gross B, et al.: Integration of biological networks and gene expression data using Cytoscape. Nat Protoc 2007, 2(10):2366-2382.

Cowan, G, Feldman M: Preview of Workshop on Complex Adaptive Systems. Bull Santa Fe Institute 1986, 1:11.

Davidsson, P: Agent based social simulation: A computer science view. J Artif Societies Social Simul 2002, 5(1). 
De Nooy, W, Mrvar A, Batagelj V: Exploratory social network analysis with Pajek, Vol. 34. Cambridge, UK: Cambridge Univ Pr; 2011.

$\mathrm{Dia}, \mathrm{H}$ : An agent-based approach to modelling driver route choice behaviour under the influuence of real-time information. Transportation Res Part C: Emerging Technol 2002, 10(5-6):331-349.

Dijkstra, E: A note on two problems in connexion with graphs. Numerische mathematik 1959, 1:269-271.

Epstein, J, Axtell R: Growing Artificial, Societies: Social Science from the Bottom up. Cambridge, MA, USA: The MIT Press; 1996.

Galaskiewicz, J, Wasserman S: Social network analysis. Sociological Methods \& Res 1993, 22:3-22.

Gardy, J, Johnston J, Sui S, Cook V, Shah L, Brodkin E, Rempel S, Moore R, Zhao Y, Holt R, et al.: Whole-genome sequencing and social-network analysis of a tuberculosis outbreak. New England J Med 2011, 364(8):730-739.

Gilbert, G, Troitzsch K: Simulation for the social scientist. New York City, USA: Open Univ Pr; 2005.

Gimblett, H: Integrating Geographic Information Systems and Agent-Based Modeling Techniques for Simulating Social and Ecological Processes. USA: Oxford University Press; 2002.

Girvan, M, Newman M: Community structure in social and biological networks. Proc Nat Acad Sci 2002, 99(12):7821.

Grimm, V, Berger U, Bastiansen F, Eliassen S, Ginot V, Giske J, Goss-Custard J, Grand T, Heinz S, Huse G, et al.: A standard protocol for describing individual-based and agent-based models. Ecol Modell 2006, 198:115-126.

Grimm, V, Revilla E, Berger U, Jeltsch F, Mooij W, Railsback S, Thulke H, Weiner J, Wiegand T, DeAngelis D: Pattern-oriented modeling of agent-based complex systems: lessons from ecology. Science 2005, 310(5750):987-991.

Fortino, G, Russo W: ELDAMeth: A Methodology For Simulation-based Prototyping of Distributed Agent Systems. Inf Software Technol 2012, 54(6):608-624 doi:10.1016/j.infsof.2011.08.006.

Hanisch, D, Zien A, Zimmer R, Lengauer T: Co-clustering of biological networks and gene expression data. Bioinformatics 2002, 18(suppl 1):S145-S154.

Hoffmann, R: The metaphor, unchained. Am Scientist 2006, 94(5):406-407.

Holcombe, M, Adra S, Bicak M, Chin S, Coakley S, Graham A, Green J, Greenough C, Jackson D, Kiran M, et al.: Modelling complex biological systems using an agent-based approach. Integr Biol 2012, 4:53-64.

Holland, J: Studying complex adaptive systems. J Syst Sci Complexity 2006, 19:1-8.

Høye, T, Skov F, Topping C: Interpreting outputs of agent-based models using abundance-occupancy relationships. Ecol Indicators 2012, 20:221-227.

lantovics, B: Agent-based medical diagnosis systems. Comput Inf 2012, 27(4):593-625.

Jiang, H, Karwowski W, Ahram T: Applications of agent-based simulation for human socio-cultural behavior modeling. Work: A J Prev, Assess and Rehabilitation 2012, 41:2274-2278.

Junker, B, Klukas C, Schreiber F: VANTED: A system for advanced data analysis and visualization in the context of biological networks. BMC Bioinformatics 2006, 7:109.

Kim, Y, Choi T, Yan T, Dooley K: Structural investigation of supply networks: A social network analysis approach. Operations Manage 2011, 29(3):194-211.

Kitano, H, Funahashi A, Matsuoka Y, Oda K: Using process diagrams for the graphical representation of biological networks. Nat Biotechnol 2005, 23(8):961-966.

Kohler, T: Dynamics in Human and Primate Societies: Agent-Based Modeling of Social and Spatial Processes. USA: Oxford University Press; 2000.

Krishnamurthy, E: Agent-based Models in Synthetic Biology: Tools for Simulation and Prospects. Int J Intell Syst. 2012, 4.

Lewis, K, Gonzalez M, Kaufman J: Social selection and peer influence in an online social network. Proc Nat Acad Sci 2012, 109:68-72.

López-Paredes, A, Edmonds B, Klugl F: Special Issue: Agent Based Simulation of Complex Social Systems. Simulation 2012, 88:4-6.

Luna, F, Stefansson B: Economic Simulations in Swarm: Agent-based modelling and object oriented programming, Volume 14. New York, USA: Springer; 2000.

Macal, C, North M: Tutorial on agent-based modelling and simulation. J Simulation 2010, 4(3):151-162.

Macal, C, North M: Successful approaches for teaching agent-based simulation. J Simulation 2012 doi:10.1057/jos.2012.1.

Macy, M, Willer R: From factors to actors: Computational sociology and agent- based modeling. Annu Rev Sociology 2002, 28:143-166.

Maere, S, Heymans K, Kuiper M: BiNGO: a Cytoscape plugin to assess overrep-resentation of gene ontology categories in biological networks. Bioinformatics 2005, 21(16):3448-3449.

Mansury, $Y$, Kimura M, Lobo J, Deisboeck T: Emerging patterns in tumor systems: simulating the dynamics of multicellular clusters with an agent-based spatial agglomeration model. J Theor Biol 2002, 219(3):343-370.

McGloin, JM, Kirk DS: Social Network Analysis. In Handbook of Quantitative Criminology. Edited by Piquero, AR, Weisburd D. New York: Springer; 2010:209-224.

Miller, J, Page S: Complex Adaptive, Systems: An Introduction to Computational Models of Social Life. Princeton, NJ, USA: Princeton Univ Pr; 2007

Mitchell, M: Complex systems: Network thinking. Artif Intelligence 2006, 170(18):1194-1212.

Milo, R, Shen-Orr S, Itzkovitz S, Kashtan N, Chklovskii D, Alon U: Network motifs: simple building blocks of complex networks. Science's STKE 2002, 298(5594):824.

Minar, N, Burkhart R, Langton C, Askenazi M: Santa Fe Institute, Santa Fe N: The swarm simulation system: A toolkit for building multi-agent simulations. In Advancing Social Simulation: The First World Congress. Santa Fe, NM: Santa Fe Institute; 1996.

Niazi, MA: Towards A Novel Unified Framework for Developing Formal, Net- work and Validated Agent-Based Simulation Models of Complex Adaptive Systems. PhD thesis 2011.

Niazi, MA, Hussain A: A novel agent-based simulation framework for sensing in complex adaptive environments. Sens J, IEEE 2011a, 11(2):404-412.

Niazi, MA, Hussain A: Agent-based computing from multi-agent systems to agent-based models: a visual survey. Scientometrics 2011b, 89(2):479-499. 
Niazi, MA, Hussain, A: Sensing emergence in complex systems. IEEE Sens J 2011C, 11(10):2479-2480

Niazi, M, Hussain A: Social network analysis of trends in the consumer electronics domain. In Consumer Electronics (ICCE), 2011 IEEE International Conference on: IEEE; 2011d:219-220.

Niazi, MA, Hussain A: Cognitive Agent-based Computing-l: A Unified Framework for Modeling Complex Adaptive Systems Using Agent-based and Complex Network-based Methods. Berlin, Germany: Springer Verlag; 2012.

Niazi, MA, Hussain A, Kolberg M: Verification and validation of agent based simulation using, VOMAS approach. In Proceedings of the Third Workshop on Multi-Agent Systems and Simulation'09 (MASS '09), as part of MALLOW 09. Torino, Italy; 2009.

North, MJ, Howe TR, Collier NT, Vos JR: A Declarative Model Assembly Infrastructure for Verification and Validation. In Advancing Social Simulation: The First World Congress. Edited by Takahashi, S, Sallach DL, Rouchier J. Heidelberg, FRG: Springer; 2007

North, M, Macal C: Managing business complexity: discovering strategic solutions with agent-based modeling and simulation. USA: Oxford university press; 2007.

Qu, H, Norman D, Lu Z: Digital orange tree: An intelligent agent based simulation model. Afr J Agric Res 2012, 7(5):690-710.

Railsback, S, Grimm V: Agent-Based and Individual-Based Modeling: A Practical Introduction. Princeton, New Jersey: Princeton Univ $\mathrm{Pr} ; 2011$

Railsback, S, Lytinen S, Jackson S: Agent-based simulation platforms: Review and development recommendations. Simulation 2006, 82(9):609-623.

Read, M, Andrews P, Timmis J, Kumar V: Techniques for grounding agent-based simulations in the real domain: a case study in experimental autoimmune encephalomyelitis. Math Comput Modell Dynamical Syst 2012, 18:67-86.

Reuter, J, Mathews D: RNAstructure: software for RNA secondary structure prediction and analysis. BMC Bioinformatics 2010, 11:129.

Russell, S, Norvig P: Artificial Intelligence: A Modern Approach: Prentice hall; 2010.

Scott, J: Social network analysis. Sociology 1988, 22:109-127.

Shannon, P, Markiel A, Ozier O, Baliga N, Wang J, Ramage D, Amin N, Schwikowski B, Ideker T: Cytoscape: a software environment for integrated models of biomolecular interaction networks. Genome Res 2003, 13(1 1):2498-2504

Shen-Orr, S, Milo R, Mangan S, Alon U: Network motifs in the transcriptional regulation network of Escherichia coli. Nature Genet 2002, 31:64-68.

Sklar, E: NetLogo, a multi-agent simulation environment. ArtifLife 2007, 13(3):303-311.

Sueur, C, Jacobs A, Amblard F, Petit O, King A: How can social network analysis improve the study of primate behavior? Am J Primatology 2011, 73(8):703-719.

Team, N: Network Workbench Tool. 2006. [http://nwb.slis.indiana.edu].

Tesfatsion, L: Agent-based computational economics: Growing economies from the bottom up. Artiflife 2002, 8:55-82.

Tesfatsion, L: Agent-based computational economics: modeling economies as complex adaptive systems. Inf $\mathrm{SC}$ 2003, 149(4):262-268

Tesfatsion, L, Judd K: Handbook of Computational Economics: Agent-Based Computational Economics, Volume 2. Amsterdam, Netherlands: North Holland; 2006.

Tian, J, Hahner J, Becker C, Stepanov I, Rothermel K: Graph-based mobility model for mobile ad hoc network simulation. In Simulation Symposium, 2002. Proceedings. 35th Annual. San Diego, California, USA: IEEE; 2002:337-344.

Tsugawa, S, Ohsaki H, Itoh Y, Ono N, Kagawa K, Takashima K, Imase M: Toward large-scale and dynamic social network analysis with heterogeneous sensors in ambient environment. In Virtual Reality Workshops (VR), 2012: IEEE; 2012:1-2.

Vidal, J: Fundamentals of, Multiagent Systems: Using NetLogo Models. South Carolina, Columbia, SC, USA: University of South Carolina; 2006

Vidal, J, Buhler P, Goradia H: The past and future of multiagent systems. In Proceedings of AAMAS Workshop on Teaching Multi-Agent Systems. New York, NY: ACM; 2004

Wilensky, U: NetLogo. 1999. Center for Connected Learning and Computer-Based Modeling, Northwestern University. Evanston, IL. [http://ccl.northwestern.edu/netlogo/].

Windrum, P, Fagiolo G, Moneta A: Empirical validation of agent-based models: Alternatives and prospects. $J$ Artifl Societies and Social Simul 2007, 10(2):8

Yang, S, Knoke D: Social Network Analysis. Thousand Oaks, USA: Sage Publications, Inc; 2008.

doi:10.1186/2194-3206-1-1

Cite this article as: Niazi: Complex Adaptive Systems Modeling: A Multidisciplinary Roadmap. Complex Adaptive Systems Modeling 2013 1:1. 